\title{
Perceptions of the medicinal value of hallucinogenic drugs among college students
}

\author{
JARED I. WILDBERGER ${ }^{1 *}$, CASSANDRA N. JOHN ${ }^{2}$ and ROBERT M. HALLOCK ${ }^{2}$ \\ ${ }^{1}$ Department of Psychology, Towson University, Towson, MD, USA \\ ${ }^{2}$ Department of Psychology, Purdue University Northwest, Hammond, IN, USA
}

(Received: November 22, 2016; accepted: September 7, 2017)

\begin{abstract}
Background: This survey examined perceptions among college students about the potential medicinal benefits of hallucinogenic drugs. Current research and potential benefits include an ability to help anxiety, post-traumatic stress disorder, and addiction with hallucinogen-assisted psychotherapy. Methods: We devised and administered a survey on 124 students at two college campuses, one small private college in the mid-Atlantic and one medium-sized public university in the Midwest of the United States. Results: Responses were similar across campuses, and in general, participants were reluctant to agree that hallucinogens can be therapeutic to the seven afflictions we questioned them about. However, the survey also revealed that a majority of participants believed there should be further research done exploring the medicinal benefits of such drugs. Conclusion: These findings shed light on perceptions of hallucinogens as their use is being applied to a host of afflictions.
\end{abstract}

Keywords: hallucinogens, college survey, psychedelic therapy, drug trends, LSD

\section{INTRODUCTION}

Hallucinogenic drugs have a history of being both accepted and rejected in our society. For example, the mescalinecontaining peyote plant was therapeutically used by Native Americans for over 5,000 years, and was even commercially sold in the early 20th century in the United States (Calabrese, 2007). On the other hand, when hallucinogenic plants were used by shamans and healers in the middle ages, they became associated with witchcraft and paganism and their usage was condemned (Schultes, Hofmann, \& Rätsch, 1979). The laboratory study of hallucinogens began with Hofmann's synthesis of lysergic acid diethylamide (LSD) in 1938. Since then, hallucinogen-assisted psychotherapy has been used to treat many treatment-resistant psychiatric disorders. Psychotherapy sessions with hallucinogens were beneficial to those with addictions (Krebs \& Johansen, 2012). Furthermore, in England, there were outpatient centers for hallucinogenassisted psychotherapy. However, many of the experiments during this period were largely anecdotal, lacked a control group, or had other experimental flaws (Sigafoos, Green, Edrisinha, \& Lancioni, 2007). Despite these methodological shortcomings, hallucinogens were a promising and emerging option to treating mental illness. Furthermore, hallucinogens are largely safe when administered in a controlled environment (Gasser et al., 2014; Ludewig, Ludewig, Hasler, \& Vollenweider, 2003), and are ingested both recreationally and for self-treatment of various conditions or afflictions (Spring, Ostrow, \& Hallock, 2016).

Public opinion began taking a negative stance on hallucinogens during the 1960s. The Central Intelligence Agency had begun their own testing into the drugs after the Second World War and found that they produced negative mental reactions, including suicide (Marks, 1979). As recreational use of hallucinogens grew, panic grew as hospitals began admitting individuals with "LSD-induced schizophrenia," coupled with misguided fears of the drug's ability to damage the human chromosome (Cohen, Marinello, \& Back, 1967; Ungerleider, Fisher, \& Fuller, 1966). Hallucinogenic drugs like LSD eventually became federally outlawed in the United States in 1968 (Grob, 1994; Lee \& Shlain, 1985). Similarly, methylenedioxymethamphetamine was once seen as a promising therapeutic drug (Buffum \& Moser, 1986; Sessa, 2012) until public deaths occurred and studies overestimating the drug's potential harm were published (Gouzoulis-Mayfrank et al., 2000; Ricaurte, Yuan, Hatzidimitriou, Cord, \& McCann, 2002).

A small resurgence of research on the utility of hallucinogens began in the 1990s (Strassman, 2001). Since 2000, hallucinogens have been tested to treat obsessive-compulsive disorder (Moreno, Wiegend, Taitano, \& Delgado, 2006), depression (Zarate et al., 2006), anxiety-associated with end-stage cancer (Gasser, Kirchner, \& Passie, 2015), posttraumatic stress disorder (Amoroso, 2015; Mithoefer, Wagner, Mithoefer, Jerome, \& Doblin, 2010), nicotine addiction (Johnson, Garcia-Romeu, Cosimano, \& Griffiths, 2014), and additional studies with other applications are ongoing.

Here, we examined the views of college student on the medicinal properties and adverse effects of hallucinogenic drugs. Recent research has shown that college students positively view certain hallucinogens, and most users describe the experience as beneficial in some manner (CarhartHarris \& Nutt, 2010; Hallock, Dean, Knecht, Spencer, \&

\footnotetext{
* Corresponding author: Jared I. Wildberger; Department of Psychology, Towson University, 8000 York Road, Towson, MD 21252, USA; Phone: +1 301305 4482; E-mail: jared.wildberger@, yahoo.com
} 
Taverna, 2013). Here, we sought to extend the findings of Hallock et al. (2013) and investigate whether recent positive findings from scientific research were impacting the views of college students about the drugs. We administered a survey on two college campuses that geographically differed and by the demographics of the student body.

\section{METHOD}

\section{Participants - College A}

The participants were 69 college students from a small, liberal arts college in the mid-Atlantic region of the United States. In total, $50.7 \%$ of the samples were males, whereas $49.3 \%$ were females. Furthermore, $65.2 \%$ self-reported as Caucasian or White, $17.4 \%$ African-American or Black, $10.1 \%$ Latino or Hispanic, $2.9 \%$ Chinese or Asian, and $4.3 \%$ mixed. The age range was $18-23(M=19.7)$. Participants were randomly recruited in their dorms by the researcher asking if they had a minute to complete a survey on hallucinogenic drugs and no incentive was given to participate. Surveys were administered between 18:00 and 22:00. The survey was approved by Hood College's Institutional Review Board.

\section{Participants - College B}

The participants were 55 college students from a mid-largesized college in the Midwest of the United States. Of the participants, $53.7 \%$ were males, whereas $46.3 \%$ were females. Furthermore, $61.1 \%$ self-reported as Caucasian or White, 3.7\% African-American or Black, 29.63\% Latino, Hispanic, or Mexican, whereas the rest indicated mixed or did not specify. The age range was $18-35(M=21.3)$. Participants were randomly selected for participation and recruited from popular places around campus at different times and on different days, and no incentive was given. The survey was approved by Purdue University's Institutional Review Board.

\section{Materials and procedures}

First, the participants were read an informed consent script by the interviewer, explaining that they could refuse the survey and withdraw at any time without penalty. They were told that the survey was about hallucinogenic drugs, which included "LSD, mushrooms, and ecstasy," but not marijuana. If the participant agreed to the survey, the interviewer would then proceed with the questionnaire in the order that is presented in Table 1.

The questionnaire consisted of three demographic questions (age, ethnicity, and gender; all self-reported), and 13 questions that assessed potential benefits and negative effects of the drug. For example, "I believe hallucinogenic drugs can be used to treat anxiety." These questions were on a 5-point Likert scale with answers ranging from "strongly disagree" to "strongly agree." Two questions asked the participants if they believed hallucinogenic drugs should be studied further for their medicinal value, one question asked the participant if they felt hallucinogenic drugs can be enjoyed safely when used recreationally, and one question

Table 1. College students' views on hallucinogenic drugs

\begin{tabular}{|c|c|c|c|c|c|}
\hline$N=124$ & Strongly disagree & Disagree & Neutral & Agree & Strongly agree \\
\hline $\begin{array}{l}\text { I would say I am knowledgeable about } \\
\text { hallucinogenic drugs, } N=124\end{array}$ & $12(9.7 \%)$ & $19(15.3 \%)$ & $30(24.2 \%)$ & $49(39.5 \%)$ & $14(11.3 \%)$ \\
\hline $\begin{array}{l}\text { Hallucinogenic drugs can be a therapeutic tool for } \\
\text { those with anxiety, } N=123\end{array}$ & $2(1.6 \%)$ & $29(23.6 \%)$ & $44(35.8 \%)$ & $41(33.3 \%)$ & $7(5.7 \%)$ \\
\hline $\begin{array}{l}\text { Hallucinogenic drugs can be a therapeutic tool for } \\
\text { those with depression, } N=123\end{array}$ & $4(3.3 \%)$ & $30(24.4 \%)$ & $46(37.4 \%)$ & $37(30.1 \%)$ & $6(4.9 \%)$ \\
\hline Hallucinogenic drugs can be addictive, $N=124$ & $1(0.8 \%)$ & $12(9.7 \%)$ & $20(16.1 \%)$ & $50(40.3 \%)$ & $41(33.1 \%)$ \\
\hline $\begin{array}{l}\text { Hallucinogenic drugs can be a therapeutic tool for } \\
\text { those with migraines, } N=124\end{array}$ & $2(1.6 \%)$ & $31(25 \%)$ & $50(40.3 \%)$ & $37(29.8 \%)$ & $4(3.2 \%)$ \\
\hline $\begin{array}{l}\text { Hallucinogenic drugs can be safely enjoyed when } \\
\text { used recreationally, much like alcohol or } \\
\text { tobacco, } N=123\end{array}$ & $13(10.6 \%)$ & $36(29.3 \%)$ & $27(21.9 \%)$ & $39(31.7 \%)$ & $8(6.5 \%)$ \\
\hline $\begin{array}{l}\text { Hallucinogenic drugs can be a therapeutic tool to } \\
\text { aid in smoking cessation, } N=124\end{array}$ & $4(3.2 \%)$ & $42(33.9 \%)$ & $47(37.9 \%)$ & $24(19.4 \%)$ & $7(5.6 \%)$ \\
\hline $\begin{array}{l}\text { Hallucinogenic drugs can be a therapeutic tool for } \\
\text { those with severe mental disorders, } N=123\end{array}$ & $9(7.3 \%)$ & $36(29.3 \%)$ & $43(34.9 \%)$ & $30(24.4 \%)$ & $5(4.1 \%)$ \\
\hline $\begin{array}{l}\text { Hallucinogenic drugs should be tested for their } \\
\text { medicinal value, } N=122\end{array}$ & $2(1.6 \%)$ & $2(1.6 \%)$ & $16(13.1 \%)$ & $67(54.9 \%)$ & $35(28.7 \%)$ \\
\hline $\begin{array}{l}\text { Hallucinogenic drugs can be detrimental to one's } \\
\text { mental health, } N=120\end{array}$ & $1(0.8 \%)$ & $12(10 \%)$ & $34(28.3 \%)$ & $50(41.7 \%)$ & $23(19.2 \%)$ \\
\hline $\begin{array}{l}\text { Hallucinogenic drugs can be a therapeutic tool for } \\
\text { those with drug or alcohol addictions, } N=124\end{array}$ & $15(12.1 \%)$ & $35(28.2 \%)$ & $44(35.5 \%)$ & $28(22.6 \%)$ & $2(1.6 \%)$ \\
\hline $\begin{array}{l}\text { Hallucinogenic drugs can be a therapeutic tool for } \\
\text { those with chronic pain, } N=123\end{array}$ & $2(1.6 \%)$ & $22(17.9 \%)$ & $44(35.8 \%)$ & $45(36.6 \%)$ & $10(8.1 \%)$ \\
\hline $\begin{array}{l}\text { The federal government should fund studies to } \\
\text { explore medicinal uses for hallucinogenic } \\
\text { drugs, } N=124\end{array}$ & $6(4.8 \%)$ & $9(7.3 \%)$ & $26(20.9 \%)$ & $60(48.4 \%)$ & $23(18.5 \%)$ \\
\hline
\end{tabular}


stated "I would say I am knowledgeable about hallucinogenic drugs," the term "knowledgeable" being self-defined. These questions utilized the Likert scale in their answers as described above. There was also one question that asked if the participant was aware of ongoing experiments looking at the medicinal uses of hallucinogenic drugs, which was a yes/no question. Furthermore, at the Midwestern college, participants were asked if they had previously used a hallucinogenic drug, and responses to this question were "yes," "no," or "prefer not to answer." Table 1 shows a list of the questions asked and how they were presented to the respondents. Participants were then thanked for their time and given a debriefing form.

\section{RESULTS}

Data between colleges were similar, so they were pooled. Of the 124 survey respondents, 50.9\% agreed or strongly agreed that they were "knowledgeable about hallucinogenic drugs." Of the participants to comment on the safety of such drugs, $39.9 \%$ strongly disagreed or disagreed with the statement "hallucinogenic drugs can be safely enjoyed when used recreationally, much like alcohol or tobacco," whereas $38.2 \%$ agreed or strongly agreed with that statement.

Questions regarding the possible medicinal uses of hallucinogenic drugs for anxiety, depression, smoking cessation, and other applications were asked and data are presented in Table 1. There were also questions on the perceived negative effects of hallucinogenic drugs. In total, $73 \%$ of the sample agreed or strongly agreed that "hallucinogenic drugs can be addictive." Furthermore, $61 \%$ of participants believed that "hallucinogenic drugs can be detrimental to one's mental health."

In terms of medical potential, $82.6 \%$ agreed or strongly agreed that "hallucinogenic drugs should be tested for their medicinal value." As for the question regarding the federal government funding such studies, $66.9 \%$ agreed or strongly agreed to federal funding for research of hallucinogenic drugs. As for previous use, $27 \%$ of respondents reported having taken a hallucinogenic drug $(N=14)$. This is a comparable rate to similar findings with this population, as Hallock et al. (2013) found the use of psilocybin-containing mushrooms to be $29.5 \%$ among the college students. Finally, $74 \%$ of the sample reported being unaware of current hallucinogenic research $(N=122)$. Full results can be seen in Table 1.

$\chi^{2}$ analyses compared the answers for the questions between users and non-users. Users and non-users showed significant differences on their use of hallucinogens as a potential tool for those with anxiety, $\chi^{2}(4, n=50)=12.22$, $p<.05$. However, users and non-users did not show significant differences to any of the other questions, $p$ values $>.05$ for each of these comparisons.

\section{DISCUSSION}

Overall, students were reluctant to agree to potential medicinal applications of hallucinogenic drugs. In all, seven questions assessed whether hallucinogenic drugs could be a therapeutic tool to various afflictions, and the responses were generally neutral. Among these questions, there was an average of $32.8 \%$ supporting that hallucinogens can be therapeutic to those with the stated conditions/afflictions. Furthermore, most survey respondents (67.2\%) believed that hallucinogenic drugs were addictive and that they could be harmful to one's mental health. Most students, however, agreed that there should be further research into the medicinal benefits of hallucinogens $(82.6 \%)$ and that the federal government should fund such studies (66.9\%). Regarding recreational use, an equivalent number of people agreed that hallucinogens can be safely used in recreational settings $(38.2 \%)$ as those who disagreed with the statement $(39.9 \%)$.

Interestingly, $50.8 \%$ of the sample $(N=63)$ reported that they were "knowledgeable about hallucinogenic drugs." Of these, $43.5 \%$ believed that hallucinogens could be safely used recreationally, compared with $38.2 \%$ of the overall sample. Furthermore, the knowledgeable group similarly responded to the total population when asked if they believed that hallucinogenic drugs could be addictive: $75.8 \%$ of the knowledgeable group and $73.4 \%$ of the total population reported that the drugs were addictive $(9.7 \%$ of the knowledgeable group disagreed, whereas $14.5 \%$ were neutral). This is interesting because hallucinogens are generally considered non-addictive, especially compared with other recreational substances (Canal \& Murnane, 2017). However, this knowledgeable group is also the group most likely to be aware of the ongoing hallucinogenic studies, as $38.7 \%$ of them said they were aware $(N=24)$ compared with $26.2 \%(N=32)$ in the total sample. Finally, it was interesting that there were not many differences in responding between the users and non-users to the survey questions. The only question that reached statistical significance between the two groups was whether hallucinogens could be used to treat anxiety, with the users reporting more potential benefits than the non-users. A total of $78 \%$ of users agreed or strongly agreed that hallucinogens could be used to treat anxiety compared with only $50 \%$ of non-users. In line with this finding, other studies have reported that hallucinogenic drug users cite relaxation as a reason for using the drug (Hallock et al., 2013), and Grob et al. (2011) reported lasting benefits of hallucinogens on anxiety of cancer patients.

Selection bias could be present as a confound for this study, as selection was limited only to the college students who were on campus during the data collection. Similarly, commuter students were entirely left out of college A's recruitment, just from the fact that they would not be living in the dorms where recruitment took place. However, college B was carefully sampled at different times of day in more central places around campus, and the data between the two colleges did not differ. The wording of the questions could have also been a limitation, as the use of the word "can" could lead to some ambiguity. In addition, the phrase "severe mental disorders" could be open to interpretation. Furthermore, an online survey might have yielded more information given the taboo nature of the subject, as compared with the face-to-face interviews this study conducted. There seems to be some differences between this study and previous online surveys regarding hallucinogenic drug use, but whether that is due to the differences in survey procedures is unclear. 
There is a lot of ambivalence surrounding participant's impressions of the medicinal uses as indicated in the results, as is evidenced by so many answers of "neutral." Despite this, however, the majority of college students support further research even on a federal level. The lack of knowledge on current medical applications to the drugs lags behind knowledge gained from actual scientific findings. The perceptions unmasked here may undercut their eventual use if they are approved and prescribed for various afflictions.

Funding sources: There were no sources of funding for this study.

Authors' contribution: JW: principal investigator, data collector, writer, statistical analysis, and survey development; CNJ: data collection and writer; RMH: writer, editor, statistical analysis, and survey development.

Conflict of interest: The authors declare no conflict of interest.

Ethics: All data collection was conducted in accordance with the Declaration of Helsinki.

\section{REFERENCES}

Amoroso, T. (2015). The psychopharmacology of $\pm 3,4$ methylenedioxymethamphetamine and its role in the treatment of posttraumatic stress disorder. Journal of Psychoactive Drugs, 47(5), 337-344. doi:10.1080/02791072.2015.1094156

Buffum, J., \& Moser, C. (1986). MDMA and human sexual function. Journal of Psychoactive Drugs, 18(4), 355-359. doi:10.1080/02791072.1986.10472369

Calabrese, J. D. (2007). The therapeutic use of peyote in the Native American Church. In M. J. Winkelman, T. B. Roberts, M. J. Winkelman, \& T. B. Roberts (Eds.), Psychedelic medicine: New evidence for hallucinogenic substances as treatments (Vol. 2, pp. 29-42). Westport, CT: Praeger Publishers/Greenwood Publishing Group.

Canal, C. E., \& Murnane, K. S. (2017). The serotonin 5-HT2C receptor and the non-addictive nature of classic hallucinogens. Journal of Psychopharmacology, 31(1), 127-143. doi:10.1177/ 0269881116677104

Carhart-Harris, R. L., \& Nutt, D. J. (2010). User perceptions of the benefits and harms of hallucinogenic drug use: A web-based questionnaire study. Journal of Substance Use, 15(4), 283-300. doi:10.3109/14659890903271624

Cohen, M. M., Marinello, M. J., \& Back, N. (1967). Chromosomal damage in human leukocytes induced by lysergic acid diethylamide. Science, 155(3768), 1417-1419. doi:10.1126/ science.155.3768.1417

Gasser, P., Holstein, D., Michel, Y., Doblin, R., Yazar-Klosinski, B., Passie, T., \& Brenneisen, R. (2014). Safety and efficacy of lysergic acid diethylamide-assisted psychotherapy for anxiety associated with life-threatening diseases. The Journal of
Nervous and Mental Disease, 202(7), 513-520. doi:10.1097/ NMD.0000000000000113

Gasser, P., Kirchner, K., \& Passie, T. (2015). LSD-assisted psychotherapy for anxiety associated with a life-threatening disease: A qualitative study of acute and sustained subjective effects. Journal of Psychopharmacology, 29(1), 57-68. doi:10.1177/0269881114555249

Gouzoulis-Mayfrank, E., Daumann, J., Tuchtenhagen, F., Pelz, S., Becker, S. V., Kunert, H. J., Fimm, B., \& Sass, H. (2000). Impaired cognitive performance in drug free users of recreational ecstasy (MDMA). Journal of Neurology, Neurosurgery, and Psychiatry, 68(6), 719-725. doi:10.1136/jnnp.68.6.719

Grob, C. S. (1994). Psychiatric research with hallucinogens: What have we learned? Yearbook for Ethnomedicine and the Study of Consciousness, 3, 91-112.

Grob, C. S., Danforth, A. L., Chopra, G. S., Hagerty, M., McKay, C. R., Halberstadt, A. L., \& Greer, G. R. (2011). Pilot study of psilocybin treatment for anxiety in patients with advancedstage cancer. Archives of General Psychiatry, 68(1), 71-78. doi:10.1001/archgenpsychiatry.2010.116

Hallock, R. M., Dean, A., Knecht, Z. A., Spencer, J., \& Taverna, E. C. (2013). A survey of hallucinogenic mushroom use, factors related to usage, and perceptions of use among college students. Drug and Alcohol Dependence, 130(1-3), 245-248. doi:10.1016/j.drugalcdep.2012.11.010

Johnson, M. W., Garcia-Romeu, A., Cosimano, M. P., \& Griffiths, R. R. (2014). Pilot study of the 5-HT2AR agonist psilocybin in the treatment of tobacco addiction. Journal of Psychopharmacology, 28(11), 983-992. doi:10.1177/ 0269881114548296

Krebs, T. S., \& Johansen, P.-Ø. (2012). Lysergic acid diethylamide (LSD) for alcoholism: Meta-analysis of randomized controlled trials. Journal of Psychopharmacology (Oxford, England), 26(7), 994-1002. doi:10.1177/0269881112439253

Lee, M. A., \& Shlain, B. (1985). Acid dreams: The CIA, LSD and the sixties rebellion. New York, NY: Grove Weidenfeld.

Ludewig, S., Ludewig, K., Hasler, F., \& Vollenweider, F. X. (2003). No lasting effects of moderate doses of MDMA (ecstasy) on memory performance and mood states in healthy humans. Biological Psychiatry, 53(Suppl), 205S.

Marks, J. (1979). The search for the "Manchurian Candidate". New York, NY: Dell.

Mithoefer, M. C., Wagner, M. T., Mithoefer, A. T., Jerome, L., \& Doblin, R. (2010). The safety and efficacy of \pm 3 , 4-methylenedioxymethamphetamine-assisted psychotherapy in subjects with chronic, treatment-resistant posttraumatic stress disorder: The first randomized controlled pilot study. Journal of Psychopharmacology, 25(4), 439-452. doi:10.1177/0269881110378371

Moreno, F. A., Wiegend, C. B., Taitano, E. K., \& Delgado, P. L. (2006). Safety, tolerability, and efficacy of psilocybin in 9 patients with obsessive-compulsive disorder. Journal of Clinical Psychiatry, 67(11), 1735-1740. doi:10.4088/JCP. v67n1110

Ricaurte, G. A., Yuan, J., Hatzidimitriou, G., Cord, B. J., \& McCann, U. D. (2002). Severe dopaminergic neurotoxicity in primates after a common recreational dose regimen of MDMA (“ecstasy"). Science, 297(5590), 2260-2263. doi:10.1126/ science. 1074501

Schultes, R. E., Hofmann, A., \& Rätsch, C. (1979). Plants of the Gods (pp. 14-48). New York, NY: McGraw-Hill. 
Sessa, B. (2012). Could MDMA be useful in the treatment of PTSD? Progress in Neurology and Psychiatry, 15(6), 4-7. doi:10.1002/pnp.216

Sigafoos, J., Green, V. A., Edrisinha, C., \& Lancioni, G. E. (2007). Flashback to the 1960s: LSD in the treatment of autism. Developmental Neurorehabilitation, 10(1), 75-81. doi:10.1080/13638490601106277

Spring, M. G., Ostrow, R. D., \& Hallock, R. M. (2016). A profile of those who use hallucinogenic mushrooms. In V. R. Preedy (Ed.), Neuropathology of drug addictions and substance misuse (Vol. 2). London, UK: Elsevier.

Strassman, R. (2001). DMT: Spirit molecule (pp. xi-40). Rochester, VT: Park Street Press.
Ungerleider, J. T., Fisher, D. D., \& Fuller, M. (1966). The dangers of LSD. Analysis of seven months' experience in a university hospital's psychiatric service. Journal of American Medical Association, 197(6), 389-392. doi:10.1001/jama.1966.031100 60063015

Zarate, C. J., Singh, J., Carlson, P. J., Brutsche, N. E., Ameli, R., Luckenbaugh, D. A., Charney, D. S., \& Manji, H. (2006). A randomized trial of an N-methyl-D-aspartate antagonist in treatment-resistant major depression. Archives of General Psychiatry, 63(8), 856-864. doi:10.1001/archpsyc. 63.8 .856 